\title{
An Investigation of Relationship between Bank Service Quality Dimensions Based on BSQ Model and Customers' Satisfaction, Case Study: Refah Bank, Tehran City
}

\author{
${ }^{*}$ Hossein Vazifehdoost \\ Department of Business Management, Science and Research Branch, Islamic Azad University, Tehran, Iran \\ *Corresponding Author: Email: Vazifehdust@yahoo.com
}

Seyyed Ahad Raeiszadeh

Department of Business Management, Science and Research Branch, Islamic Azad University, Tehran, Iran

\author{
Doi:10.5901/mjss.2015.v6n5s2p483
}

\begin{abstract}
In today's world, measurement of customers' satisfaction is very important. Customer's satisfaction is a feeling and it should be turned into a quantitative index in order to improve it. Models of customer's satisfaction indices are solutions for this conversion process. Data collection for this process is also conducted by questionnaire and different techniques. In order to measure customer's satisfaction, first we should develop product/service-customer matrix. Then, we determine targets and technique for filling questionnaires is selected and we calculate their impact coefficientsand effective factors. The present research tries to investigate customer's satisfaction using bank services quality dimensions based on BSQ model in Refah Bank in Tehran west branch City. This research is a descriptive survey. Respondents were selected by means of simple random sampling in Refah Bank customers in Tehran city. 300 questionnaires were collected. Correlation and regression techniques were used for data analysis. Finally, the results of hypotheses test showed that all dimensions of bank service quality based on BSQ model have significant and positive relationship with customers.
\end{abstract}

Keywords: customers' satisfaction, service quality dimensions, BSQ model

\section{Introduction}

Serving customers is the oldest and also newest issue for any firm. Most commentators believe that the most certain way to remain in customers' minds is to improve service quality. Contrary to products which have special features like durability and defective items, services are intangible and inhomogeneous. Every customer's experience of services he or she receives is different from other customers. Furthermore, production and consumption of service quality cannot be separated from each other because services are produced by firms and consumed by customers (Tavanazadeh and Aligholi, 2014). Within the past years, customers' needs in relation to levels of service quality have received a lot of attention. High levels of service provision are a means for reaching competitiveadvantages. As customers' awareness of bank services increases, they become more and more sensitive to the quality of services they receive. In order to maintain a long-term relationship along with customers' satisfaction, banks should know how they can provide highqualityservices. Provision of high-quality services maybe is the main factor in customer's satisfaction and only institutes which have comprehensive viewpoint of customers can provide stable services. Service quality and customers' satisfaction concepts have received a lot of attention in marketing texts within the past few decades. Marketing researchers have admired satisfaction and quality advantages and consider them as indices for competitive advantage. The exact nature of customers' judgement and relationship between these two concepts is still ambiguous (Ruyter, Bloemer\&Peeters, 1997).

\subsection{Theoretical Fundamentals}

The present era is the age if ongoing developments and companies are confronted with unprecedented harsh competitive conditions due to factors like unclear borders of markets, fragmentation of markets, short product life cycles and rapid changes in purchase models of customers and increased awareness of customers (Vazifehdoost, Vaezi\&Tavanazadeh, 2014). For decades, the real value of a company was measured in terms of assets, tangible properties, factories and equipment of the company. However, researchers found that the real value of a company lies something beyond, in 
potential purchasers' minds (Heidarzadeh, Khoshpanjeh and Rahnama, 2011). In any organization, whether a production or a service company, the main factor for survival of the organization is customer, and if an organization fails to attract customers' loyalty will not reach long-term growth (Rahnama et al, 2012). Within the past years, customers' needs in relation to levels of service quality have received a lot of attention. High levels of service provision are a means for reaching competitiveadvantages. As customers' awareness of bank services increases, they become more and more sensitive to the quality of services they receive. In customers' strategy, loyalty of customer is of strategic importance for any organization. Increase in customer's loyalty has received a lot of attention in managers and advisors and scholars (Haghighi et al, 2012).

\subsection{Definition of service quality}

In traditional approach, quality of products relied on physical features like durability and reliability but many companies know that if a product does not satisfy customers' needs and expectations will not be ideal even if it is the most successful product in the world (Roosta et al, 2001). Quality is a complex concept and has many directions (Shields, 1999). Its definition is difficult because of many implicit criticisms. Having a customer orientation for products and services is more useful than all other definitions (Sahney, Banwet\&karunes, 2004). YarMohammadiyan (2004), as quoted from Tarker, believes that quality is a multi-faceted concept. Value perceptions, general intentions and special targets of any individual or beneficiary group comprise bases for quality. From Peters' viewpoint, quality lies in the eyes of an observer of mind of a consumer and changes with impression and attitudes of individuals (Muhammadi, 2005). Service quality is an important factor for organizational growth, success and survival and is considered as a strategic, effective and comprehensive subject for management (Sanni et al, 2006). Most texts which deal with service quality view it from two aspects: from a producer's viewpoint or a consumer's viewpoint. However, it must be noted that most definitions in the field of service quality refer to "customer orientation". For instance, Lewis, Moore and Kreidoon defined quality as "performing according to or consistent with customers' expectations" (Ghobadiyan, 1994). In fact, it can be said that a service has quality which can satisfy customers' needs and expectations and the provided services are consistent with or beyond customers' needs.

\subsection{A glance at service concept}

Service is an activity which is conducted based on demand and there is a price to it in the market. Service is an economic and non-physical product which is produced by a person, firm or industry and any firm which has an intangible product is considered as a service firm. Services include intangible activities and bring satisfaction. However, it does not involve ownership of an object (Ranjbariyan, 2002). Many researchers have long emphasized on service quality as one of the strategic values of organizations in service sector (Lewis, 1991). Service quality has many advantages for a firm. It allows the firm to reach higher sales and differentiate it from competitors and maintain customers' satisfaction (Arasli, Smadi, \&Katircioglu, 2005).

\subsection{Models for measurement of service quality}

There are many models for service quality and we mention only a few of them.

\subsection{Lehtinen and Lehtinen model}

They presented three dimensions for service quality:

- Physical quality: physical quality refers to products or supportive items pf products and services. Financial products have limited physical dimensions and are usually other physical evidence are used for evaluation of service quality. For instance, customers evaluate quality based on decoration, facilities inside branches buildings and .... .

- Interactive quality: interactive quality refers to interactions between customers and service providers. These interactions may occur in different ways. For instance, interactions may be face-to-face or via instruments like telephone or internet.

- Organizational quality: organizational quality refers to mental image of an organization and is an intangible dimension. Therefore, it refers to perceptions of general organizational quality mentioned above (Harrison, 2000). 


\subsection{Gronrous model}

Geronrous introduced three dimensions when discussing about service quality:

- Technical quality of outcome: technical quality or outcome refers to real outcome of service after the service was evaluated. Outcome is what a customer receives from an organization. Service outcome is usually evaluated objectively by consumers.

- Functional quality of process: functional or process quality refers to the quality of processes and procedures in production and service provision for customers. Considering the process of production and consumption of services which are usually occurred simultaneously, process quality is usually evaluated by customer when doing a service. This elementof quality refers to interaction between provider and receiver and is perceived mentally.

- Corporate image: this dimension is related to customer's perceptions of service organization. Image depends on the quality of output, price, external relational activities, physical status, decoration and cleanliness of branch, competency and behavior of employees. This factor acts like a filter. Gronrous explains: "if corporate image is good in a particular customer's mind, the problems this customer has with the result or process will be ignored to a large degree by means of mental image. If problems take place continuously, positive corporate image becomes damaged and corporate image becomes negative. In such a state, qualitative problems will be worse than what will be perceived really (SeyeydJavadin and Kimiasi, 2005).

\subsection{Servqual model}

This service quality model was presented by Parasuraman et al (1985). It is now a standard instrument for measurement of service quality. In service quality literature, it is known as SERVQUAL model. this instrument has 22 pairs of dimensions in its general and primary form. Half of these dimensions evaluate the expected level of quality from customer's viewpoint and the other half evaluates the perceived quality presented by that special organization or company. This may be resulted from simplicity of perception of service quality and internal organizational factors. After doing basic studies in the field of service quality, the standards obtained were proposed in the form of SERVQUAL model. Service quality or SERVQUAL is made up of two keywords: service and quality. In this model, after investigation of customers' expectations with service quality, we determine gaps between factors affecting service quality (management perception, features of service quality, quality of services provided for customers, relationship with customers) and expectations identified in the first stage (Akbariyan, 2004).

\subsection{Customer satisfaction concept}

Customer's satisfaction is an important issue for contemporary organizations. Today, failure or success of an organization depends on customers' satisfaction with products and services. Customer's satisfaction increases customer loyalty and loyal customersspend more money on buying company products. They encourage others to buy from the organization. Customer's satisfaction increases repetitive purchases and decreases customers' complaints. Satisfied customers are less sensitive to price, buy side products and are affected less possibly by competitors and remain loyal (Atafar and Shafiee, 2006). Satisfaction of customers' needs make them content (Kotler, 2004). Successfulness or failure of companies depends on the fact that how many percent of customers they can maintain? Maintenance of a large number of customers is a success. In a fiercely competitive environment, a company without customer orientation will be at risk because in such markets a firm needs to produce high-quality services and products. Today, according to figure 1 , customer satisfaction lies between product quality and customer satisfaction from one hand and profitability from the other hand and is considered as a main target for commercial organizations (Fiscova, 2004).

\subsection{Research conceptual model}

BSQ model was used for measurement of service quality in order to satisfy customers. Bahia and Nantel (2000) talked about SERVQUAL and criticized its defects. They mainly emphasized on absence of comprehensiveness and general nature of the instrument. They believed that in some services, other dimensions ae added to SERVQUAl. The present research is based upon Bahia and Nantel's model (Bahia and Nantel, 2000). 


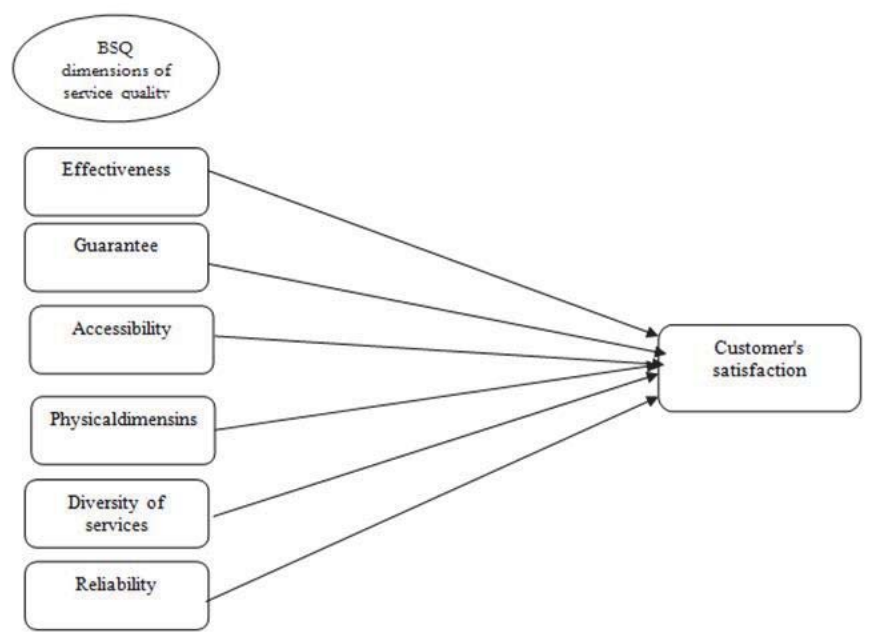

Figure 1. Research conceptual model

Considering research conceptual model, research hypotheses are as follows:

\subsection{Research hypotheses}

- customer's satisfaction has a significant relationship with effectiveness of bank services.

- customers' satisfaction has a significant relationship with bank services guarantee.

- customers' satisfaction has a significant relationship with bank services accessibility.

- customers' satisfaction has a significant relationship with appearance of bank services.

- customers' satisfaction has a significant relationship with diversity of bank services.

- customers' satisfaction has a significant relationship with reliability of bank services.

\section{Materials and Methods}

\subsection{The questionnaire}

Questionnaire wasused for collection of data. Five-point Likert scale was used for questions, from "completely agree" to "completely disagree". The present questionnaire was designed by Bahi and Nantel in 2002. After preparation of the questionnaire, 25 questionnaires were distributed among Refah Bank customers as a pretest and in order to investigate reliability of the questionnaire. Cronbach's alpha was used for reliability investigation. Results showed that Cronbach's alpha was above 0.7 for all dimensions and total questionnaire. Further, reliability of the questionnaire was also verified by scholars. Therefore, the questionnaire was valid and reliable enough to be distributed among sample members.

Sample

Statistical population of the research included all customers who used Refah Bank services in Tehran city. Because population was not limited and there were multi-valued variables, the following equation was used for determination of sample size.

$$
n=\frac{Z_{a / 2}^{2} \times P(1-P)}{\varepsilon^{2}} \quad n=\frac{(1.96) \times 0.5 \times 0.5}{(0.06)^{2}}=267
$$

$Z$ : is standard normal probability, alpha is error level, $P$ is success ratio and epsilon is precision (Moeni, Fa'alGhayyoumi, 2005). Certainty level was equal to $p 5 \%$ and precision was $6 \%$. Because there was no estimation for success ratio, it was equal to 0.5 . sample size in this case is increased to its maximum. 


\section{Data Analysis}

\subsection{Investigation of normality of variables}

Kolmogrov-Smearnov test was used for investigation of normality of variables. The results of this test have been presented in table 1.

Table 1: results of Kolmogrov-Smearnov test

\begin{tabular}{|ll|c|c|c|c|c|c|c|c|}
\hline & & Effectiveness & Guarantee & Accessibility & & $\begin{array}{c}\text { Physical } \\
\text { dimensions }\end{array}$ & $\begin{array}{c}\text { Diversity of } \\
\text { services }\end{array}$ & Reliability & Satisfaction \\
\hline Number & & 267 & 267 & 267 & 267 & 267 & 267 & 267 & 267 \\
Normality parameters & Mean & 3.4252 & 3.1759 & 3.5422 & 3.6632 & 3.5473 & 3.4892 & 3.3324 & 3.4998 \\
& SD & .64112 & .87654 & .74352 & .65402 & .71092 & .78932 & .85432 & .69876 \\
Maximum differences & Absolute & .102 & .102 & .113 & .144 & .089 & .134 & .129 & .114 \\
limit & Positive & .094 & .089 & .081 & .138 & .089 & .123 & .120 & .114 \\
Test statistics & Negative & -.105 & -.105 & -.116 & -.160 & -.084 & -.135 & -.139 & -.111 \\
Sig( & & .105 & .105 & .116 & .160 & .084 & .141 & .138 & .115 \\
\hline
\end{tabular}

As it can be seen in table 1, all significance numbers of research variables are significant. In other words, distribution of the variables is not normal. Therefore, we used non-parametric methods for data analysis.

Research hypotheses test

Correlation test was used for testing research hypotheses. Considering the non-normal distribution of variables, Spearman correlation test was used for data analysis. The results of hypotheses test using Spearman correlation coefficient have been summarized in table 2 .

Table 2. Research hypotheses test

\begin{tabular}{|l|l|l|}
\hline Hypothesis & Correlation intensity & )Sig( \\
\hline customer's satisfaction has a significant relationship with effectiveness of bank services. & 0.68 & 0.000 \\
\hline customers' satisfaction has a significant relationship with bank services guarantee. & 0.34 & 0.000 \\
\hline customers' satisfaction has a significant relationship with bank services accessibility. & 0.55 & 0.000 \\
\hline customers' satisfaction has a significant relationship with appearance of bank services. & 0.52 & 0.000 \\
\hline customers' satisfaction has a significant relationship with diversity of bank services. & 0.50 & 0.000 \\
\hline customers' satisfaction has a significant relationship with reliability of bank services. & 0.46 & 0.000 \\
\hline
\end{tabular}

An investigation of the research hypotheses tests reveals that allresearch hypotheses are supported. Further, effectiveness dimension has the strongest relationship with customers' satisfaction (factor loading equal to 0.68 and significance number equal to 0.000). guarantee dimension has the weakest relationship with customers' satisfaction.

\section{Conclusion and Discussion}

In today's world, measurement of customers' satisfaction is of great importance. Customer's satisfaction is a feeling and it must be quantified to improve it. Customer satisfaction models are solutions for this conversion process. Data collection for this process is also conducted by questionnaire and different techniques. Deming, one of the pioneers of quality considers quality the same as customers' satisfaction. It is clear that there is a strong relationship between customer satisfaction and his or her survival. A customer's feeling towards a product or service will determine the successfulness or defeat of that product or service. Customer's satisfaction guarantees return on investment. Customers pay money in return for receiving products and services. Without awareness of customers' expectations, customers may do not tend to use products and services and the investments may fail. In the present research, relationship between service quality and customers' satisfaction in Refah Bank in MeshkinShahr was investigated. BSQ model with dimensions like effectiveness, guarantee, accessibility, physical dimensions, services diversity and reliability were considered. These dimensions have positive and significant relationship with customers' satisfaction. As a final conclusion, there is a positive and significant relationship between service quality of Refah Bank and customers' satisfaction. In other words, all variables of BSQ model have significant relationship with customer's satisfaction. Therefore, managers of Refah Bank are proposed to try 
to improve customers' satisfaction by implementation of effective actions. This in part will result in customers' loyalty and increase market share and will result in return on investment and high profitability.

\section{References}

Akbariyan, Gholam Reza, (2004), "evaluation of service quality using five-dimensinal SERVQUAL model (case study: Tehran Customs department), master degree thesis, Tehran, ShahidBeheshti University

Atafar, Ali and Shafiee, Morteza (2006), "relationship between service quality and customer's satisfaction", fourth international conference on management.

Fecikova, K., (2004), "An index method for measurement of customer statisfaction", The TQM Magazine, 16, 57-66.Harrison, T., (2000), "Financial services marketing", Prentice Hall. Great Britain.

Haghighi, Mohammad; Dorosti, Ali; Rahnama, Afshin; Hoseinpour, Ali;(2012) Afshin; Alaei, Abbas; Shafaee, Javad; Ariana, Ali;(2012); 'Evaluation of factors affecting customer loyalty in the restaurant industry' African Journal of Business Management Vol. 6(14), pp. 5039-5046.

Heidarzadeh Hanzaee, Kambiz; Khoshpanjeh, Mahsa \& Rahnama, Afshin; "Evaluation of the effects of product involvement facets on brand loyalty" African Journal of Business Management Vol. 5(16), pp. 6964-6971, 18 August, 2011.

Mohammadi, R. J., \& et al., (2005), "Quatity evaluation in higher education: Concepts, principles and criteria", Tehran: The Organization for Measuring Education (in Persian).

Rahnama, Afshin; Alaei, Abbas; Shafaee, Javad; Hamdam, Hadi;(2012) "Evaluating the Impact of Banking Services Quality on Customer Loyalty in Mellat Bank Ardebil Province" Journal of Basic and Applied Scientific Research, 2(3)2498-2506.

Roosta, Ahmad, Venous, Davar and Ibrahimi, Abdolhamid (2001), "marketing management", Tehran: SAMT publications, fifth printing.

Ruyter, K. D., Bloemer, J., \& Peeters, P., (1997), "Merging service quality and service satisfaction, an empirical test of an integrative model", Journal of Economic Psychology, 18, 387-406.

Sahney, S., Banwet, D. K., \& karunes, S., (2004), "Comceptualizing total quality management in higher education", The TQM Magazine, $16,145-159$.

Sahney, S., Banwet, D. K., \& Karunes, S., (2006), "An integrated framework for quality in education: A pplication of quality function deployment, interpretive structural modeling and path analysis", Total Quality Management, 17, 265-285.

SeyyedJavadin, Seyyed Reza and Kimiasi, Masoud (2005), "service quality management", Tehran: Negah-eDanesh publications, first printing.

Shields, P. M., (1999), "Zen and the art of higher education maintenance: Bridging classic and romantic notions of quality", Journal of Higher Education Policy and Management, 21, 165-172.

Tavanazadeh, Somayeh., Aligholi, Mansoureh., (2014). "Investigation of Relationship between Service Quality Dimensions and Customers' Satisfaction (case study: Saderat Bank Branches in Tehran City, Iran)" Mediterranean Journal of Social Sciences, Vol 5 № 20, 3116-3120.

Vazifehdoost, Hossein; Vaezi, Maryam \& Tavanazadeh, Somayeh., (2014). "Investigation of the Role of Innovation Dimensions and Knowledge-Based Trust in Accepting Mobile Banking" Journal of Applied Environmental and Biological Sciences Vol 5(2), 106112. 